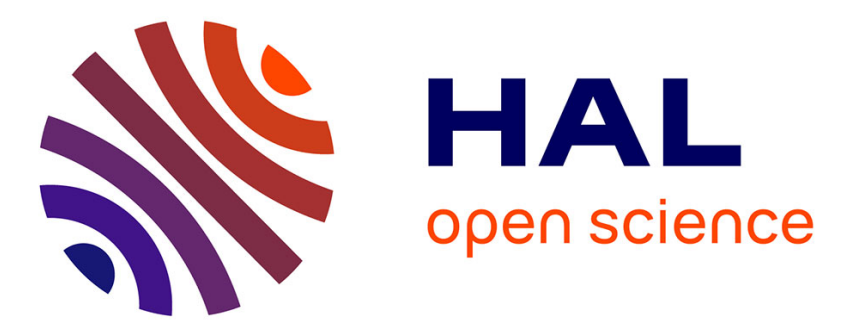

\title{
Establishing Networks for the Treatment of WEEE Components
}

\author{
Mohammadtaghi Falsafi, Rosanna Fornasiero
}

\section{To cite this version:}

Mohammadtaghi Falsafi, Rosanna Fornasiero. Establishing Networks for the Treatment of WEEE Components. 17th Working Conference on Virtual Enterprises (PRO-VE), Oct 2016, Porto, Portugal. pp.652-660, 10.1007/978-3-319-45390-3_56. hal-01614610

\section{HAL Id: hal-01614610 \\ https://hal.inria.fr/hal-01614610}

Submitted on 11 Oct 2017

HAL is a multi-disciplinary open access archive for the deposit and dissemination of scientific research documents, whether they are published or not. The documents may come from teaching and research institutions in France or abroad, or from public or private research centers.
L'archive ouverte pluridisciplinaire HAL, est destinée au dépôt et à la diffusion de documents scientifiques de niveau recherche, publiés ou non, émanant des établissements d'enseignement et de recherche français ou étrangers, des laboratoires publics ou privés. 


\title{
Establishing Networks for the Treatment of WEEE Components
}

\author{
Mohammadtaghi Falsafi ${ }^{1,2, *}$, Rosanna Fornasiero ${ }^{1}$ \\ ${ }^{1}$ ITIA-CNR Institute of Industrial Technologies and Automation, Via Corti 12, \\ 20133, Milan, Italy \\ ${ }^{2}$ Politecnico di Milano, Department of Mechanical Engineering, Via la Masa 1, 20157, Milan, \\ Italy \\ \{mohammadtaghi.falsafi, rosanna.fornasiero\}@itia.cnr.it
}

\begin{abstract}
This paper analyzes different approaches for managing Waste Electronic and Electrical Equipment (WEEE) in order to reduce the economic and environmental impacts and in particular how to manage collaborative networks. The classifications are made based on the review of the recent and related literature in WEEE treatment and show the impacts on different cases studied in the literature. In addition, a simulation model is proposed to study the practical impact of improving the capability of a Region to treat WEEE components.
\end{abstract}

Keywords: Waste Electrical and Electronic Equipment (WEEE), Supply chain models, Simulation

\section{Introduction}

The aim of this study is to propose an innovative model to evaluate the cost of implementing networks to recover/recycle Waste of Electronic and Electrical Equipment (WEEE) components. To reach this aim, it is first studied different models of WEEE supply chain management from literature from which some important parameters for the evaluation of the cost of the networks emerge. Most of the models consider distance between treatment centres and collection centres, type of vehicles to use in transportation of WEEE, type of supply chain structure and also agents to collect the WEEE as well as the product residual value. Some of these criteria have been taken into consideration for the creation of the model to analyse the costs of the creation of a WEEE components treatment network.

This paper describes a detailed analysis of the creation of collaborative networks for handling the flow of WEEE in an Italian region and consider the re- and demanufacturing process of one important component which is the Printed Circuit Board (PCB). The proposed model allows to evaluate the costs for establishing a collaborative network where treatment centres and de-manufacturing plants can work

\footnotetext{
* Corresponding author
} 
together to improve the capability of a Region to recycle components from End-ofLife products. In particular, in section 2, the proposed classification of the models for WEEE treatment in the present literature is explained which are chosen based on the scope of this paper. In section 3, a simulation model is described and applied to a specific case related to the Italian WEEE treatment activity and in section 4 results of the proposed model are discussed. Finally, section 5 explains the final remarks and proposed suggestions for the future improvement in this context.

\section{Literature Review of Supply Chain Models for WEEE Management}

In literature there are different approaches and definitions for distinguishing treatment centers and collection centers. In general, collection centers are the points where WEEE is collected from different sources (private citizens, communities, electric equipment retailers with the duty to assure a certain percentage of collection upon what they sell) and sometimes disassembled to main components; treatment centers are specialized in disassembly of WEEE and WEEE components and also in some occasions these centers are referred to as treatment plants where the recycling and remanufacturing of WEEE is implemented.

\subsection{Models to Identify the Critical Factors for WEEE Management}

In literature, it is possible to find several studies defining the critical factors for the management of WEEE. In Kim et al. (2006) [1], the re-manufacturing process of reusable parts in reverse logistics is discussed; manufacturer has two options as providing the components from the suppliers or recover its own products. In this study, critical factors are identified as the type of collected products from customers, the quantity of parts required by manufacturing plants, the parts for assembling each product, the products to go to the subcontractor for re-manufacturing as outsourcing, the refurbished parts from re-manufacturing operations, the parts purchased from external supplier, and the number of disposed parts. Considering these critical factors, it is proposed a model which determines the number of remanufactured components in order to reduce the costs.

In case of Gobbi et al. (2011) [2], the role of the product residual value (PRV) and the loss of value over time of returned products are considered critical factors in the context of reverse logistics while in Luglietti et al. (2014) [3], the environmental and economic impacts of engine re-manufacturing process is based on three options for EOL automotive engine as reuse, re-manufacturing and material recovery.

The concepts of collaboration and collaborative networks are considered important in reverse logistics according to what Romero and Molina (2013) [4] have discussed and in Frayret et al. (2001) [5] have emphasized this role in the collaborative programs implemented in business practices. There are other important aspects of collaborative networks in reverse logistics which are analysed like the impact of sustainability [6] and the impact of IT [7] and both of them can give some suggestions for this work. In Bigum et al. (2012) [8], metal recovery from high-grade WEEE is 
discussed and the results of the study show that the environmental impacts could be positively justified and applied.

\subsection{Facility Location Models of WEEE Collection Points}

Another important issue in reverse supply chain management is finding the best location for collection points. In Barba-Gutiérrez et al. (2008) [9], the importance of WEEE transportation and its effect on environment is discussed and for the specific case, it is suggested to keep the distance between below $500 \mathrm{~km}$, in order to have recycling activities which are not economically and environmentally efficient.

More recently in Vidovic et al. (2011) [10], a novel approach to position the collection points of end-of-life vehicles (ELVs) is introduced based on the concept of multiple service zones. The service zones are obtained based on centroids of each area with one collection point and this approach has been partially applied also to this work as a way to define where to locate the new plants. Grunow et al. (2009) [11] present three different models based on optimization for managing WEEE collection in Denmark and analyze the location of the collection points to guarantee the dispersion of collection points in a small scale problem.

Melo et al. (2009) [12] analyze the facility location model based on strategic planning and define four key characteristics which can be useful also for this paper which are: multi-layer facilities, multiple commodities, single/multiple period(s), and the use of deterministic/stochastic parameters.

In Queiruga et al. (2008) [13] it is suggested a model to rank allocation of Spanish municipalities based on factors like land costs, personnel costs, energy prices, and facility access. The result shows that the large cities have priority in this case while by considering other factors other different results are obtained. In Ponce-Cueto et al. (2012) [14] an optimization model is analyzed for a location and allocation problem in different dimensions (local, regional, central) in the context of reverse logistics. Their aim is to minimize the total cost by considering facility operation, waste handling, transportation, and disposal.

\subsection{Models to Close the Loop of the Supply Chain of WEEE}

This section considers the models which study closed-loop of the WEEE supply chain management. In Savaskan et al. (2001) [16] considering different take-back channel structures, the best agent to collect WEEE is explored. Three scenarios are defined as: the manufacturer is responsible for the reverse flow of the products, the retailers are responsible to take the products back to the cycle, and to outsource the recycling activities. In the context of decentralized system, the authors conclude that the coordination of manufacturer and retailers is the best scenario.

Implication of different types of supply chain mentioned above is studied in Savaskan et al. (2004) [17] where the models are compared with respect to the wholesale price, the retail price, the product return rate, and the total supply chain profits. The study defines that the optimal product return rate of the coordinated channel is the highest followed by retailers, manufacturers and third parties respectively. It is shown that the coordinated channel is more effective than the 
decentralized channel. Other models in Yang et al. (2009) [18] analyzes the supply chain in different tiers as supplier, manufacturer, retailer, consumer and recovery centers while in Cardoso et al. (2013) [19] it is defined the capacity and location of the plants for closed-loop supply chain in order to maximize the net present value.

The impact of ecological and technological issues in closed-loop supply chain with recycling activities are the two other aspects considered in Georgiadis et al. (2008) [20]. From the other point of view in a collection - re-manufacturing scheme, these EOL products can generate new profits. Also analytical models are used for reverse logistics to improve the efficiency and effectiveness of the whole system [21] while in Koh et al. (2012) [22], it is discussed that environmental issues can be dealt such that all the players in the network can collaborate in a beneficial way.

\subsubsection{Simulation Models for Supply Chain Configuration.}

Among the different quantitative approaches for managing supply chain configuration, simulation has several advantages since it gives the possibility to have a realistic observation of the dimensions to be considered when studying the characteristics of the supply chain [23] and analyse the network along a certain period of time. Therefore it can result in strategic approaches which could be useful for decision making policies [24]. In the past, several simulation approaches have been proposed for solving different types of problems related to supply chain configurations. Cigolini et al. (2014) [25] used discrete-event simulation to analyze different supply chain configurations in terms of stocks and stock-out by evaluating if intermediaries influenced product quality and costs. Ramanathan (2014) [26] implemented a simulation method by considering several performance indicators to evaluate the importance of collaboration in a supply chain, while Bottani and Montanari (2010) [27] proposed a simulation model where information sharing mechanisms in a supply chain are considered to be a way to support demand forecast.

Camarinha-Matos (2013) [6] has analyzed the Factories of the Future (FoF) in the roadmap of horizon 2020. Simulation is a subset of "customer focused manufacturing" which could also affect collaborative networks in the category of "collaborative and mobile enterprises". In literature, there are numerous studies for network configuration in reverse logistics. Some focus on the simulation (like Kara, Rugrungruang et al. (2007) [28]) Also there are some papers that analyze both the simulation and optimization together (e.g. Topcu, Benneyan et al. 2013 [29], Sadjadi, Soltani et al. 2014 [30], Martinsen, Gulbrandsen-Dahl 2015) [31]).

\section{The Model for De-manufacturing Network}

In Italy, a pilot plant has been developed to handle one important part of WEEE, which is the Printed Circuit Board (PCB) [32]. The plant is proposed to re- and demanufacture $\mathrm{PCBs}$ with dedicated innovative machines [32] to recycle metal and plastic from the PCBs of WEEEs and remanufacture the automotive PCBs. A part from the technological improvement held by this kind of pilot plant, it emerged as 
important to study how such kind of technologies can change the established networks for WEEE management in a certain area and how collaboration can change among the actors in terms of exchanging materials and information.

In order to analyze the characteristics of the system, simulation is used. The simulation model developed in this work considers different types of nodes:

- Source nodes: Treatment centers where the WEEE is dismantled to its raw material. The model assumes that there are treatment centers that have only WEEE with low value from where only PCBs and other treatment centers from where PCBs with high value can arrive.

- Re- and de-manufacturing plants: These plants are to be located in the existing local network and in the model it is assumed that they are located close to some treatment centers.

- Sinks: They are the plants that are potential destinations for the output of re- and de-manufacturing plants. The outputs are metal and plastic. The location of the plants is based on the plants already exist in the region that have the potentiality or readiness to collect the outputs.

- $\quad$ PCBs with low value will follow only the de-manufacturing process while PCBs with high value will follow first a verification on their residual value and then in case it is high, they go to the re-manufacturing process; otherwise they go to the de-manufacturing process.

It is assumed that each entity (transportable unit) in the simulation corresponds to the truck capacity; all the trucks start from the same node (home node); when the simulation starts running all the trucks start travelling from that node and when they are idle they go back until next load is available. The logic of choosing the home node is related to the density of plants and treatment centers in the region; more specifically, the de-manufacturing plant which has more density compared to the other plants is the home node.

When a truck loads in a treatment center, it goes to the assigned plant to unload, then if any output is ready for pick-up at the plant, the truck loads it and take it to the destinations, otherwise it travels to the closest treatment centers. When a truck unloads in the destinations, it checks for any loads ready in treatment centers or plants. There is no constraint for the trucks to move between different plants and treatment centers in all the network and regardless of the clusterization of the network.

The different what-if scenarios are built by changing number of trucks in the model and the capacity of the trucks in order to evaluate performance of the system in terms of travelling distance, truck utilization and plant capacity utilization.

\subsection{Input Data}

Since there are no official data on PCBs flows, this study considers that the amount of PCBs to be handled is on average $4.5 \%$ of the total weight of WEEE as suggested in Grosso, Rigamonti (2014) [34].

The location of the de-manufacturing plants and destinations is studied and obtained by the model proposed by Falsafi, Fornasiero (2016) [33]. For estimating the flows of PCBs for each plants, which are going to operate in the future, we need to 
foresee the future trends. These flows are calculated assuming the 5\% yearly increase of the WEEE production, attracting the flows which are currently transported to developing countries, attracting the flows which currently go to the landfill, and the ability to import WEEEs from other regions in Italy. [34]

From the PCB treatment process to be handle in the plants, it will be possible to obtain $30 \%$ of metal and $70 \%$ of plastic as output to be recycled Grosso, Rigamonti (2014) [34]. Economies of scale are also considered and the unitary cost (cost per ton) for both re- and de-manufacturing plants is linked to the plant capacity.

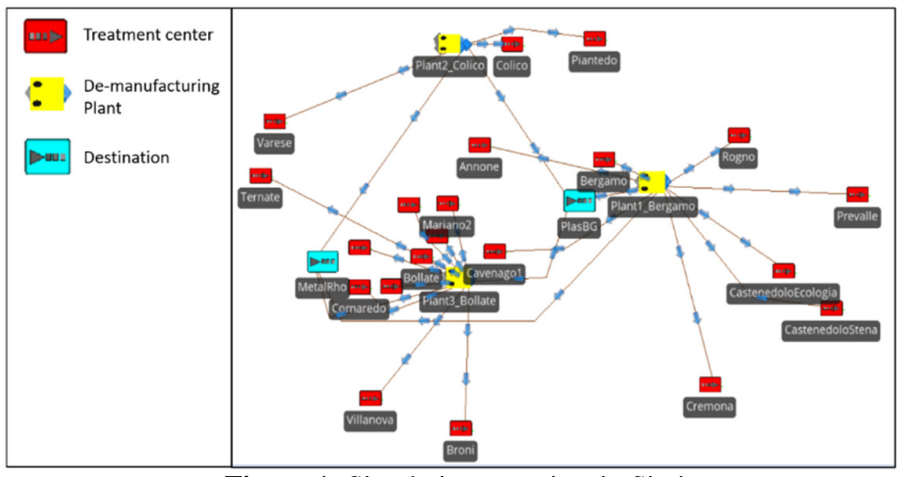

Figure 1- Simulation overview in Simio

\section{Results}

Figure 1Error! Reference source not found. shows the network view in the simulation model for de-manufacturing plants, which is done by SIMIO software. The picture shows the location of 21 treatment centers and 3 plants of an Italian Region with the two destinations for the outputs of metal and plastic. The model was tested with the current flows and with a scenario increasing the flow in the next 10 years according to the rate of increase of WEEE explained in section 3.1.

Error! Reference source not found. Table 2 shows the results of the simulation for the current and future flows for de-manufacturing plant. The trucks' utilizations are $80 \%$ and $92 \%$, which are reasonably high. In addition, by increasing the flow by 4.33 times (from current to future flow), the increase in total costs is $3 \%$ less than the increase in the total flow; this $3 \%$ stems from the more efficient performance of the plants whose costs increases by $5 \%$ less than the increase of the total flow.

Table 1- Simulation results

\begin{tabular}{lcc}
\hline & Current flow & Future flow \\
\hline Total flow (ton) & 2,327 & 10,081 \\
\hline Truck capacity (ton) & 5.8 & 5.8 \\
\hline Number of trucks & 1 & 5 \\
\hline Trucks' utilization & $80 \%$ & $92 \%$ \\
\hline Travelled distance $(\mathrm{km})$ & 67,805 & 431,333 \\
\hline Cost of the plants per year & $2,117,335$ & $8,775,966$ \\
\hline
\end{tabular}




\begin{tabular}{lcc}
\hline Number of plants & 1 & 3 \\
\hline Plants' utilization & $99 \%$ & $99 \%$ \\
\hline Total cost per year & $2,185,140$ & $9,207,299$ \\
\hline
\end{tabular}

Furthermore, in order to analyse the feasibility of the proposed model, it is useful to consider the inventory situation of the treatment centres and plants. The maximum average PCBs waiting at treatment centres is 3 tons approximatelyError! Reference source not found. The maximum average queue in the plants is 16 tons, which is relatively high and therefore, should be considered for further analysis in managing the inventories in the plants. In addition, on average each load is held around 1 working day or less (depending on the 3 plants based on the "average holding time"Error! Reference source not found.) and this shows that the proposed configuration and the operation of the plants are in the feasible criteria.

\section{Conclusion}

The classifications proposed in this paper shows the variety of approaches towards the treatment of WEEE in literature. More specifically, the key factors analysed in the studies are very different from one another and mostly are based on the purposes of the case studies and some of them have been used also in this work as a reference. Accordingly, the case study in this paper is based on a model for strategic supply chain planning to close the loop in a re-manufacturing process. The model emphasizes the importance of collaborative networks by coordinating the activities of different treatment centres with the existence of new plants for treated one specific WEEE component. The proposed simulation model could be used in similar case studies both in small- and large-scale problems with different indicators considering the purpose of the studies.

The optimal configuration should also consider the feasibility of the project regarding the inventory status. A rough analysis shows that while there is no concern related to the treatment centres, the warehouse of the plants should be designed in a way that could have the capacity equal to the maximum of the waiting PCBs obtained from the simulation. One solution for reducing the plants' inventory level is to use trucks with lower capacity. Therefore, one future study is defining scenarios with different truck capacities and analyse their effect on inventory levels.

\section{References}

1. Kim, K., Song, I., Kim, J., Jeong, B.: Supply planning model for remanufacturing system in reverse logistics environment. Computers \& Industrial Engineering, 51(2), 279-287 (2006)

2. Gobbi, Chiara.: Designing the reverse supply chain: the impact of the product residual value. International Journal of Physical Distribution \& Logistics Management 41.8, 768796 (2011)

3. Luglietti, R., Taisch, M., Magalini, F., Cassina, J., Mascolo, J. E. (2014, June). Environmental and economic evaluation of end-of-life alternatives for automotive engine. 
In Engineering, Technology and Innovation (ICE), 2014 International ICE Conference on (pp. 1-9). IEEE.

4. Romero, D., Molina, A.: Reverse-green virtual enterprises and their breeding environments: closed-loop networks. Collaborative Systems for Reindustrialization 589598. Springer Berlin Heidelberg. (2013)

5. Frayret, J.M., Cloutier, L., Montreuil, B., D’Amours, S.,: A distributed framework for collaborative supply network integration. E-Business and Virtual Enterprises 233-243. Springer US. (2001)

6. Camarinha-Matos, L. M.: Collaborative systems in support of reindustrialization. Collaborative Systems for Reindustrialization 3-10. Springer Berlin Heidelberg. (2013)

7. Olorunniwo, F. O., Li, X.: Information sharing and collaboration practices in reverse logistics. Supply Chain Management: An International Journal, 15(6), 454-462. (2010)

8. Bigum, Marianne, Line Brogaard, Thomas H. Christensen.: Metal recovery from highgrade WEEE: a life cycle assessment. Journal of hazardous materials 207, 8-14 (2012)

9. Barba-Gutiérrez, Yolanda, B. Adenso-Diaz, Matthias Hopp.: An analysis of some environmental consequences of European electrical and electronic waste regulation Resources. Conservation and Recycling 52.3, 481-495 (2008)

10. Vidovic, M., Dimitrijevic, B., Ratkovic, B., Simic, V.: A novel covering approach to positioning ELV collection points. Resources, Conservation and Recycling, 57, 1-9 (2011)

11. Grunow, Martin, Chiara Gobbi.: Designing the reverse network for WEEE in Denmark. CIRP Annals-Manufacturing Technology 58.1, 391-394 (2009)

12. Melo, M. Teresa, Stefan Nickel, Francisco Saldanha-Da-Gama.: Facility location and supply chain management-A review. European Journal of Operational Research 196.2, 401-412 (2009)

13. Queiruga, D., Walther, G., Gonzalez-Benito, J., Spengler, T.: Evaluation of sites for the location of WEEE recycling plants in Spain. Waste Management, 28(1), 181-190 (2008)

14. Ponce-Cueto, Eva, Edgar E. Blanco, Natalia Duque Ciceri.: Designing Sorting Facilities in Reverse Logistics Systems. Actes des rencontres RIRL Proceedings Logistique inversée Reverse Logistics (2012)

15. Achillas, C., Vlachokostas, C., Moussiopoulos, N., Banias, G.: Decision support system for the optimal location of electrical and electronic waste treatment plants: a case study in Greece. Waste Management, 30(5), 870-879 (2010)

16. Bottani, E., Montanari, R.: Supply chain design and cost analysis through simulation. International Journal of Production Research, 48(10), 2859-2886 (2010)

17. Kara, S., Rugrungruang, F., Kaebernick, H.: Simulation modelling of reverse logistics networks. International Journal of Production Economics, 106(1), pp. 61-69 (2007)

18. Topcu, A., Benneyan, J.C., Cullinane, T.P.: A simulation-optimisation approach for reconfigurable inventory space planning in remanufacturing facilities. Int. J. Business Performance and Supply Chain Modelling, 5(1), pp. 86-114 (2013)

19. Sadjadi, S.J., Soltani, R., Eskandarpour, A.: Location based treatment activities for end of life products network design under uncertainty by a robust multi-objective memetic-based heuristic approach. Applied Soft Computing, 23, pp. 215-226 (2014)

20. Martinsen, K., Gulbrandsen-dahl, S.: Use of Post-consumer Scrap in Aluminium Wrought Alloy Structural Components for the Transportation Sector. Procedia CIRP, 29, pp. 686691 (2015)

21. Fideas project, http://www.fideas.industries/?lang=en

22. Falsafi M., Fornasiero R.: Network configuration for re- and de-manufacturing: a case study in Italy. June 2016, Trondheim, Norway. Proceedings of $23^{\text {rd }}$ Euroma conference.

23. Grosso M, Rigamonti L. Valutazione di sostenibilità ambientale della la gestione di una categoria di rifiuto speciale in Lombardia: il caso dei RAEE. Technical report of the Lumbardy Region (2014). 